\title{
Ethephon Prolongs Dormancy and Enhances Supercooling in Peach Flower Buds
}

\author{
Edward F. Durner and Thomas J. Gianfagna \\ Rutgers Fruit Research Center, New Jersey Agricultural Experiment Station, Cook College, Rutgers \\ University, RD 2 Box 38, Cream Ridge, NJ 08514
}

Additional index words. Prunus persica, rest, chilling units, cold hardiness, low-temperature exotherms

Abstract. The heat requirement for flower bud growth of container-grown peach trees [Prunus persica (L.) Batsch. CVS. Redhaven and Springold] in the greenhouse varied inversely and linearly with the length of the cold-storage period (SC) provided to break bud dormancy. Ethephon reduced the rest-breaking effectiveness of the 5C treatment. Buds from ethephon-treated trees grew more slowly than buds from untreated trees upon exposure to 20 to $25 \mathrm{C}$, resulting in later bloom dates. The effect of ethephon on flower bud hardiness in field-grown trees of 'Jerseydawn' and 'Jerseyglo' was studied using exotherm analysis after deacclimation treatments. Bud deacclimation varied with reacclimating temperature $(7$ or $21 \mathrm{C}$ ), cultivar, ethephon treatment, and sampling date. All buds were more susceptible to injury in March than in January or February. Buds reacclimated more rapidly at 21C than at 7C. 'Jerseyglo' reacclimated more rapidly than 'Jerseydawn'. Untreated buds were less hardy and also reacclimated more rapidly than treated buds. Ethephon enhanced flower bud hardiness in three distinct ways: 1) it decreased the mean lowtemperature exotherm of pistils, 2) it increased the number of buds that supercooled after exposure to reacclimating temperatures, and 3) it decreased the rate of deacclimation, especially at $21 \mathrm{C}$. Ethephon prolongs flower bud dormancy by increasing the chilling requirement. The rate at which flower buds become increasingly sensitive to moderate temperatures in late winter and spring is thus reduced by ethephon. Thus, ethephon delays deacclimation during winter and delays bloom in the spring. Chemical name used: (2-chloroethyl) phosphoric acid (ethephon).

Peach flower buds in the eastern United States are susceptible to low-temperature injury from late winter through bloom. During dormancy, peach floral primordia supercool and, therefore, escape freezing injury (Quamme, 1978). Pistils supercool to below $-10 \mathrm{C}$ but above $-30 \mathrm{C}$. The degree of supercooling varies with water content of the pistil, which appears to be controlled by freezing, preceding the low-temperature stress (Quamme, 1983). The capacity to supercool decreases when buds are exposed to moderate temperatures $(>7 \mathrm{C})$, especially after rest has been broken by lower temperatures (0 to 7C). In the mid-Atlantic region of the eastern United States, the chilling requirement is often fulfilled by mid-January, and midwinter warm periods are commonplace. Thus, peach flower buds become increasingly susceptible to low-temperature injury from January to just before bloom, when buds will tolerate low temperatures $(-3 \mathrm{C})$ through extracellular freezing (Andrews et al., 1983b). Throughout dormancy, during bloom, and thereafter, freezing may kill a large proportion of the pistil population, resulting in economic losses.

The growth regulator ethephon decomposes to ethylene at neutral or alkaline $\mathrm{pH}$, probably in the cytoplasm of the cell (Cooke and Randall, 1968), and its effects on plant growth have been universally attributed to the ethylene produced during decomposition (Warner and Leopold, 1969; Yang, 1969). Applied to peach at low rates (100 mg.liter $\left.{ }^{-1}\right)$, in the fall, after the formation of next year's flower buds, ethephon delays further flower bud development. Immediately after application, cell division is curtailed for $\approx 7$ days (Herrera, 1986). In the spring, bloom has been delayed by as much as 10 days in New Jersey (Gian-

Received for publication 20 Mar. 1990. New Jersey Agricultural Experiment Station Publication no. D-12111-9-90, supported by state and Hatch Act funds. We thank Francis X. Rooney and Gale S. Teiger for their competent technical assistance. We also thank Frank G. Dennis, Jr., for reviewing this manuscript. Mention of trade names is for the convenience of the reader and does not constitute endorsement by the New Jersey Agricultural Experiment Station. The cost of publishing this paper was defrayed in part by the payment of page charges. Under postal regulations, this paper therefore must be hereby marked advertisement solely to indicate this fact. fagna et al., 1986) and by 16 days in New Zealand (Irving, 1987). The bloom delay increases the probability that the crop will survive frost. In addition, fall-applied ethephon increases the intrinsic hardiness of both cherry (Proebsting and Mills, 1976) and peach (Durner and Gianfagna, 1988; Proebsting and Mills, 1969) flower buds. A greater percentage of peach flower buds treated with ethephon in the fall survived - 23C (Durner and Gianfagna, 1988) and - 26C (Giafagna et al., 1989) in the field than did controls. Similar results were found with cherry and peach by Proebsting and Mills (1969, 1976). The practical consequences of increasing cold hardiness and delaying bloom can be significant, since lessening the effects of both winter cold injury and frosts during bloom can increase crop yields (Durner and Gianfagna, 1988; Gianfagna et al., 1989; Proebsting and Mills, 1976).

Little information exists on the mechanism(s) by which a single autumn application of ethephon can influence bloom date and winter hardiness of buds. Coston et al. (1985) proposed that fall ethephon applications delayed bloom by altering bud responses to moderate temperatures after rest. Crisosto et al. (1989) suggested that ethephon-induced bloom delay was due to a delay in differentiation of flower buds. Gianfagna et al. (1989) hypothesized that ethephon delays bloom and increases hardiness by reducing the rate at which flowers complete the rest period and then grow upon exposure to moderate temperatures. Whether or not ethephon alters the chilling or heat requirement and/or the supercooling ability of peach flower buds has not been determined.

Many studies of bud dormancy and cold hardiness have involved field-grown plants in which environmental conditions cannot be controlled or varied systematically. In one study, we used 2-year-old self-rooted, container-grown trees to characterize the effects of ethephon on flower bud dormancy, growth, and cold hardiness of flower buds under controlled environmental conditions. A field study coupled with deacclimation treatments in a controlled environment was also initiated to further determine the effect of fall-applied ethephon on supercooling and deacclimation in peach flower buds. 


\section{Materials and Methods}

Container-grown trees. Stem cuttings were taken from mature 'Redhaven' and 'Springold' peach trees in early Aug. 1987 and propagated as described by Couvillon et al. (1975). Rooted cuttings were transferred to 5C. After 10 weeks, cuttings were potted in Pro-Mix BX (Geiger, Harleysville, Pa.) in $21 \times 21$ $\mathrm{cm}$ (7.5 liters) plastic containers and maintained in a greenhouse held at 20 to $25 \mathrm{C}$ during the day and at a minimum of $10 \mathrm{C}$ at night. Plants received a commercial nutrient fertilizer bimonthly and were pruned to four branches per tree. The trees grew vegetatively. for $\approx 2$ months before terminal buds formed. Flower buds then differentiated in the axils of the leaves and were fully 'developed and available for use after 2 months. All experiments with container-grown trees were initiated in Oct. 1988.

Three trees with 20 to 60 flower buds per tree of both 'Redhaven' and 'Springold' were used for each treatment to characterize rest in container-grown trees. Before leaf abscission, but after the flower buds were differentiated, trees were moved to $5 \mathrm{C}$ on a 14-day schedule and held for 3 to 17 weeks. Trees for all 5C storage periods were removed on the same date and transferred to the greenhouse. Flower bud development was assessed, using a numerical rating system (Gianfagna et al., 1986), three times per week. Linear regression equations were calculated, relating percent budbreak to time at $5 \mathrm{C}$, using the regression procedure of SAS (SAS Institute, Inc., Cary, N.C.). Regression lines were forced through the origin, since at 0 weeks of chilling, $0 \%$ of the buds grew. The data from the 7- to $17-$ week cold-storage treatments were used to determine the relationship between storage time at $5 \mathrm{C}$ and the rate of bud development in the greenhouse. Parameter estimates for 'Redhaven' and 'Springold' were compared (Weisberg, 1985) to discern differences between cultivars. The number of days required for full bloom was determined by regression analysis (data not shown), and the estimated bloom dates were then regressed against the cold-storage intervals. Parameter estimates were again compared to discern differences between cultivars.

To study the effects of ethephon on flower bud dormancy and budbreak, trees were selected as previously described and treated with ethephon $\left[100 \mathrm{mg} \cdot \mathrm{liter}^{-1}+0.1 \%\right.$ polyoxyethylenepolypropoxypropanol alkyl 2-ethoxyethanol/dihydroxypropane (Regulaid) surfactant] in the greenhouse or maintained as controls. After 7 days, trees were transferred to $5 \mathrm{C}$ and held for 6,9 , or 12 weeks on a schedule such that trees in all treatments were returned to the greenhouse on the same date after the indicated cold-storage period. Flower bud development was assessed as before. The mean number of days to bloom for each cultivar/ ethephon treatment/incubation at $5 \mathrm{C}$ combination was calculated and regressed on time at $5 \mathrm{C}$. Since cultivars differed with respect to chilling requirement, the effect of ethephon was evaluated within cultivar by comparing regression parameter estimates of lines for control buds with estimates for lines from ethephontreated buds.

Only 'Redhaven' trees were used to assess flower bud hardiness of container-grown trees. Trees were treated with ethephon and controls maintained in the greenhouse as described above. and transferred 7 days later to cold rooms (7C). After 3 or 9 weeks at $7 \mathrm{C}$, three trees each from the treated and control groups were sequentially exposed to 0 or 7 days to an average of $15 \mathrm{C}( \pm 5 \mathrm{C})$ (deacclimation) then 0 or 7 days back at $7 \mathrm{C}$ (reacclimation). Trees from the 9-week chilling treatment were not reacclimated after deacclimation. The experimental design was completely random, with single-tree experimental units. After the indicated temperature regimes, low-temperature freez- ing exotherms (LTE) were determined by the method of Andrews et al. (1983a). Flower buds were excised from the stem with a small portion of bark $(\approx 1 \mathrm{~cm}$ in length) along with the intact xylem tissue. Buds were affixed to thermoelectric modules (Melcor Materials Electronics Products, Trenton, N. J.) with a thermal conducting paste (Omegatherm 201; Omega Engineering, Stamford, Corm.). Millivolt $(\mathrm{mV})$ values generated by the modules were monitored with an Omega data logger. Exotherms were detected as sudden increases in millivolts generated from the heat of fusion during freezing compared to a baseline from a control module containing paste alone. Modules were placed in a Puffer-Hubbard freezer (Rheem Scientific, Asheville, N. C.) equipped with a cam programmer and allowed to reach $-1 C$. Ice nucleation was induced by placing a $10-\mu 1$ drop of ice water on the piece of wood, followed by snow crystals. Nucleation was verified by the presence of high-temperature exotherms. Samples were then cooled at a rate of $2 \mathrm{C} /$ $\mathrm{h}$ to $-30 \mathrm{C}$. Exotherms at $-8 \mathrm{C}$ or lower were considered LTEs (Andrews et al., 1983b). A minimum of 10 buds were sampled per tree. The entire experiment was repeated for replication.

Exotherm data and proportions of buds supercooling were tested with an analysis of variance using the general linear models procedure of SAS. A factorial analysis considering chilling at 7C, ethephon treatment, and deacclimation/reacclimation as treatments was performed. Mean separation of significant effects was performed using Fisher's Protected LSD at the 0.05 level (Snedecor and Cochran, 1980).

Field studies. Ethephon (100 mg-liter ${ }^{-1}$ ) was applied to runoff to mature 'Jerseydawn' and 'Jerseyglo' peach trees on 17 Oct. 1988 to delay bloom the following spring. Regulaid was added at $0.170(\mathrm{v} / \mathrm{v})$ to assist spreading and was also used alone as a control.

Sampling dates, cultivars, and deacclimation times and temperatures used for the field studies are summarized in Table 1 . On each date, $5030-\mathrm{cm}$-long terminal shoots were randomly sampled $1 \mathrm{~m}$ from the ground from the periphery of five trees per cultivar per treatment. Twig bases were recut, and twigs placed in tap water in beakers and maintained at $7 \mathrm{C}$ or in the laboratory at $21 \mathrm{C}$. After the various deacclimation treatments, flower buds were subjected to exotherm analysis as described above. At least 10 flower buds per sample date, cultivar, ethephon treatment, temperature, and length of deacclimation were subjected to exotherm analysis.

LTE data from all sample dates were combined for a response surface regression analysis using the regression procedure of SAS. Separate regressions were performed for each cultivar/ ethephon treatment/incubation temperature combination for a total of eight analyses. The regression model used was a complete quadratic response surface model of the form: $\mathrm{Y}=\mathrm{B}_{0}+$

Table 1. Sampling date, cultivar, reacclimating temperature, and reacclimating time for field studies of deacclimation of peach flower buds treated the previous fall with ethephon for bloom delay.

\begin{tabular}{llcc}
\hline \hline Date (1989) & Cultivar & $\begin{array}{c}\text { Deacclimating temp } \\
\left({ }^{\circ} \mathrm{C}\right)\end{array}$ & $\begin{array}{c}\text { Deacclimating time } \\
\text { (days) }\end{array}$ \\
\hline 17 Jan. & Jerseydawn & 21 & $0,1,2,3,4$ \\
& Jerseyglo & 21 & $0,1,2,3,4$ \\
23 Jan. & Jerseydawn & 7 or 21 & $0,1,2,3$ \\
& Jerseyglo & 7 or 21 & $0,1,2,3$ \\
6 Feb. & Jerseydawn & 7 or 21 & $0,1,2$ \\
& Jerseyglo & 7 or 21 & $0,1,2$ \\
6 Mar. & Jerseydawn & 7 or 21 & $0,1,2,3,4$ \\
20 Mar. & Jerseyglo & 7 or 21 & $0,1,2,3$ \\
\hline
\end{tabular}


$\beta_{1} X_{1}+\beta_{11} X_{1}^{2}+\beta_{2} X_{2}+\beta_{22} X_{2}^{2}+\beta_{12} X_{1} X_{2}+\beta_{1122} X_{1}^{2} X_{2}^{2}$, where $Y=$ LTE; $X_{1}=$ field growing degree hours (GDH), base $4.5 \mathrm{C}$, accumulated before sampling and starting after the accumulation of 1000 chill units (Richardson et al., 1974); and $\mathrm{X}_{2}=$ incubation $\mathrm{GDH}$, base $4.5 \mathrm{C}$, accumulated during deacclimating after sampling from the field. Components were deleted from the model if their parameter estimate (B) was not significant $(P=0.05)$, if they increased the mean square error $\left(\delta^{2}\right)$, or if their deletion did not decrease the $R^{*}$ of the model (Weisberg, 1985). Resulting equations were statistically compared within each cultivar and incubation treatment, using the method described by Weisberg (1985), to determine if deacclimation was significantly affected by ethephon treatment. Response surface equations were significantly different if a) final equations 'contained different components or b) parameter estimates of surfaces having the same components were statistically different. Response surface regressions and parameter tests were similarly performed on the proportion of buds tested that deepsupercooled. Residual plots did not reveal a need for transformation of either LTEs or proportions supercooling.

\section{Results and Discussion}

Flower bud dormancy and budbreak of container-grown trees. The relationship between the percent budbreak and the length of cold storage for both cultivars was quadratic (Fig. 1). For 'Springold', all storage periods at $5 \mathrm{C}$ resulted in the release of some flower buds from dormancy. After 5 weeks of cold storage, $60 \%$ of the total flower buds grew; 'longer exposure had little additional effect. For 'Redhaven' all storage periods at $5 \mathrm{C}$ also released at least some buds from dormancy; however, the number of buds capable of growth did not reach a maximum (of $\approx 70 \%$, Fig. 1) until 7 weeks. Both the linear and quadratic parameter estimates for 'Springold' were statistically different from the estimates for 'Redhaven' $\left(P=0.006\right.$ for $b_{l}$ and $P=$ 0.001 for $b_{2}$ ). The chilling requirements to break flower bud dormancy of 'Springold' and 'Redhaven' are 850 and $950 \mathrm{~h}$, respectively (Fogle, 1973). Both cultivars responded to the controlled 5C dormancy-breaking conditions in a manner consistent with their chilling requirements. Bud development on 'Springold' occurred more rapidly for all cold-storage treatments, and the number of buds that were out of rest and capable of growth was greater than for ' Redhaven', particularly after 3 or 5 weeks of cold storage.

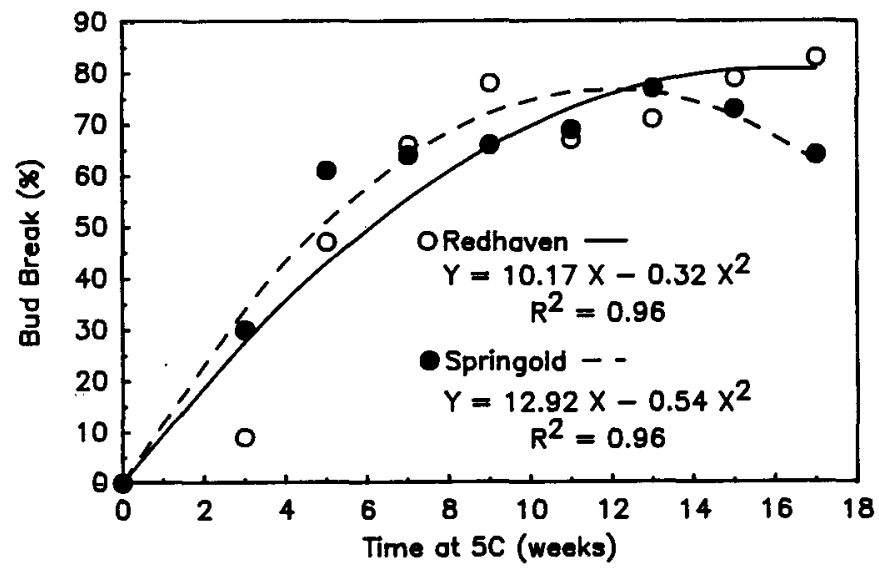

Fig. 1. Relationship between percent budbreak and storage time at SC in 'Redhaven' and 'Springold' peach flower buds. Symbols are means of three observations.
The number of days to bloom was linearly and inversely related to the length of the cold-storage period for both cultivars, with or without ethephon treatment (Figs. 2 and 3). Increasing the storage period from 7 to 13 weeks, for example, reduced the time required for full bloom by about one-half. In addition, the rate of bud growth was always greater for 'Springold' than for 'Redhaven' over the cold-storage intervals tested. 'Springold' consistently reached full bloom sooner than 'Redhaven', regardless of the amount of chilling given (Fig. 2). The effect of chilling temperatures on the rest period of flower buds is often explained by the accumulation of a finite number of chilling units that, once provided, lead to flower bud development in response to higher temperatures (Richardson et al., 1975). Additional accumulation of chilling units (postrest chilling units) (Couvillon and Erez, 1985) leads to increased rates of bud development. The data presented here support this description, in part. There is an inverse linear relationship between bud growth and accumulation of chilling units (Fig. 2). However, the time at which buds emerge from rest or endodormancy and pass into the quiescent state is difficult to determine, for there is no clear point at which the chilling requirement of the buds has been

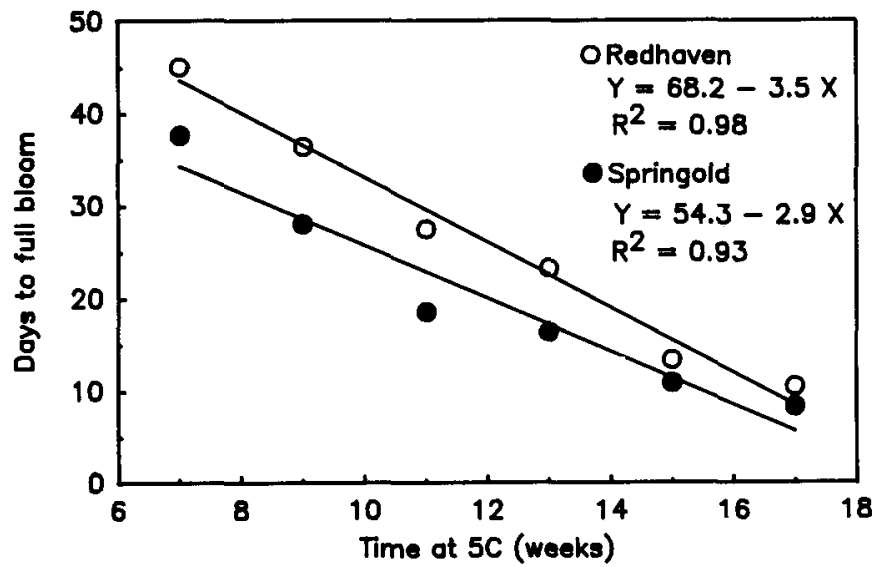

Fig. 2. Relationship between days to bloom and storage time at 5C in 'Redhaven' and 'Springold' peach flower buds. Symbols are means of three observations-.

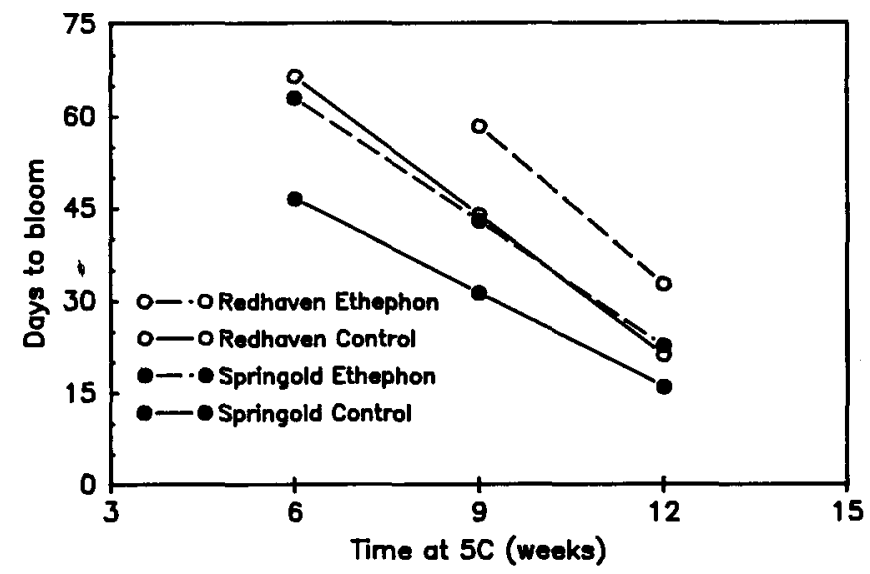

Fig. 3. Effect of ethephon on the relationship between days to bloom and storage time at 5C in 'Redhaven' and 'Springold' peach flower buds. Regression equations: 'Redhaven' control, Y $=111.84-$ 7..5583X, $R^{2}=0.97$; 'Redhaven' ethephon, $\mathrm{Y}=135.52-8.5800 \mathrm{X}$, $R^{2}=1.0$; 'Springold' control, $\mathrm{Y}=77-5.1067 \mathrm{X}, R^{\prime}=0.98$; 'Springold' ethephon, $\mathrm{Y}=103.34-6.7267 \mathrm{X}, R^{2}=0.89$. Symbols are means of three observations. 
met. Rather, flower buds respond in a continuous manner to chilling temperatures with regard to both the number of buds in the population capable of growth, as well as to their rate of growth. Separation of chilling units into pre- and postrest components may not be necessary. Increased chilling unit accumulation simply leads to quicker growth when buds are exposed to higher temperatures.

Application of ethephon to flower buds before chilling reduced the rate of flower bud growth after rest was broken by exposure to 5C. Regression line slopes for the ethephon and control comparisons within cultivar were similar $(P=0.44$ for 'Redhaven' and $P=0.22$ for 'Springold') (Fig. 3). However, the $y$-intercept estimate was greater for the ethephon treatments for both cultivars $(P=0.06$ for 'Redhaven' and $P=0.03$ for 'Springold'). The data demonstrate that ethephon delays flowering over the range of cold-storage intervals tested by reducing the effectiveness of chilling in breaking flower bud dormancy. For example, 'Springold' and 'Redhaven' flower buds treated with ethephon and maintained at 5C for 9 weeks developed at rates similar to untreated buds maintained at $5 \mathrm{C}$ for 6 weeks. Following the 6-week cold-storage period, few ethephon-treated 'Redhaven' flower buds developed in response to higher temperatures. In this case, the cold-storage period was rendered so ineffective by ethephon that few buds were released from dormancy and many abscised from the twigs. Ethephon appears to prolong flower bud dormancy, increasing the requirement for chilling unit accumulation. Crisosto et al. (1989) reported that ethephon treatment in the fall did not alter the chilling requirement of 'Redhaven' flower buds. We used 'container trees under controlled-environment conditions, while they used field trees that, undoubtedly, were subject to considerable environmental fluctuations. Coston et al. (1985) found results similar to ours. They applied the ethylene-releasing agent (2-chloroethyl) methylbis(phenylmethoy )silane to field-grown peach trees. Excised twigs taken from treated trees in midwinter and maintained in a greenhouse bore fewer flower buds capable of growth, and their growth rates were less than those of buds on control twigs. By reducing the rate at which flower buds become increasingly sensitive to moderate temperatures, ethephon treatment resulted in a delay in the time of bloom in the field.

There is little information on the role of ethylene in the regulation of bud dormancy in woody plants. Blanpied (1972) found that ethylene production in apple flower buds declined during bud expansion in the spring, and ethylene is known to inhibit bud growth in peas (Apelbaum and Burg, 1972). Others have found, however, that treatments that break bud dormancy generally result in an increase in ethylene evolution (Nell et al., 1983; Zimmerman et al., 1977), and in some corm-producing plants, such as freesia (Imanishi and Fartanier, 1983) and gladioli (Halevy et al., 1970), exogenous ethylene actually breaks dormancy. Crisosto et al. (1989) reported that internal ethylene levels in 'Redhaven' flower buds treated with ethephon in the fall were not different from levels in control buds until after chilling was completed. After rest was broken by chilling, ethylene levels were somewhat higher in ethephon-treated buds.

Flower bud cold hardiness of container-grown trees. Flower buds of container-grown trees did not supercool to the temperatures that buds from field-grown trees did. The former supercooled to between -8 and $-12 \mathrm{C}$, while the latter supercooled to between -8 and $-22 \mathrm{C}$. In addition, the proportion of flower buds that supercooled was generally $<50 \%$ for container-grown trees but $>90 \%$ for field samples before deacclimation. Con- tainer-grown trees experienced photoperiodic conditions similar to field trees during acclimation in the fall, but the first were never subjected to temperatures < 7C. During dormancy, peach floral primordia supercool and, therefore, escape freezing injury (Quamme, 1978); also, the degree of supercooling varies with water content of the pistil, which, in turn, is controlled by freezing temperatures preceding the low-temperature stress (Quamme, 1983). Flower buds from the container-grown trees in our study supercooled but did not deep-supercool. Thus, results from our hardiness study with container-grown trees should not necessarily be extrapolated to the field. Nevertheless, some interesting differences due to ethephon treatment and deacclimation on supercooling of buds were observed.

A significant interaction was detected among chilling at $7 \mathrm{C}$, ethephon, and deacclimation treatments for the mean LTE of flower buds. After 3 weeks of chilling at 7C, the mean LTE for flower buds, regardless of ethephon treatment, was - 10.7C. However, reacclimating at $15 \mathrm{C}$ for 7 days resulted in a loss in hardiness of $0.8 \mathrm{C}$ in control buds (mean LTE, - 9.9C), but did not affect hardiness of ethephon-treated buds (mean LTE, - 11.0C) $(P=0.05)$. After reacclimating, both treated and control buds supercooled to a mean LTE of $-10.7 \mathrm{C}$. After 9 weeks of chilling at $7 \mathrm{C}$, buds from ethephon-treated trees (mean LTE, $-11.8 \mathrm{C}$ ) were significantly hardier than buds from control trees (mean LTE, $-10.1 \mathrm{C})(P=0.05)$, in contrast to the results obtained after 3 weeks of chilling at $7 \mathrm{C}$.

A significant interaction was detected between length of chilling at 7C and deacclimation/reacclimation for the percentage of flower buds that exhibited supercooling. After 3 weeks of chilling at $7 \mathrm{C}, 46 \%$ of the buds that either never experienced deacclimation at $15 \mathrm{C}$, or those that were reacclimated at $15 \mathrm{C}$ followed by reacclimation at $7 \mathrm{C}$, supercooled. This percentage was significantly greater than that for buds that supercooled $(27 \%)$ after deacclimation at $15 \mathrm{C}$. However, after 9 weeks of chilling at 7C, only $16 \%$ of the flower buds supercooled, regardless of treatment. These results suggest that, in addition to the direct relationship between increased chilling and rate of bud growth (Fig. 2), increased chilling may, in itself, reduce flower bud cold hardiness.

Flower bud hardiness of field-grown trees and responses to controlled deacclimation. A fall application of ethephon lowered the supercooling temperature in flower buds of both cultivars. The mean LTE, over all dates tested, for ethephon-treated buds taken directly from the field, without additional deacclimation, was significantly lower than the mean LTE for buds from control trees (mean LTE, $-18.5 \mathrm{C}$ and $-17.6 \mathrm{C}$, respectively) $(P=0.0001)$. The effect of ethephon on deacclimation varied with cultivar and incubation temperature (Table 2, Figs. 4 and 5). Ethephon did not affect deacclimation of 'Jerseydawn' at 7C (Figs. $4 \mathrm{~A}$ vs. B). The response surface regression line for ethephon-treated buds contained the same statistically significant components as the equation for the control buds, and the parameter estimates of these equations did not differ (Table 2). However, ethephon significantly reduced deacclimation at $21 \mathrm{C}$ in 'Jerseydawn' buds (Fig. $4 \mathrm{C}$ vs. D). The response surface regression line for ethephon-treated buds contained different statistically significant components compared to the equation for the control buds (Table 2).

Ethephon significantly reduced the rate of rehardening in 'Jerseyglo' at both 7 and 21C incubation (Fig. 5). Response surface equations for ethephon-treated buds had different significant components than the equations for control buds (Table 2). The mean LTE of flower buds from both cultivars occurred 
Table 2. Regression equations, coefficients of determination $\left(R^{2}\right)$, model significance probabilities $(P>\mathrm{F})$, and number of observations (n) for low-temperature exoherms of peach pistils and proportions of pistils tested that supercooled for two cultivars treated in the fall with $100 \mathrm{ppm}$ ethephon for bloom delay, sampled after completion of the chilling requirement, followed by postsampling incubation at 7 or $21 \mathrm{C}$.

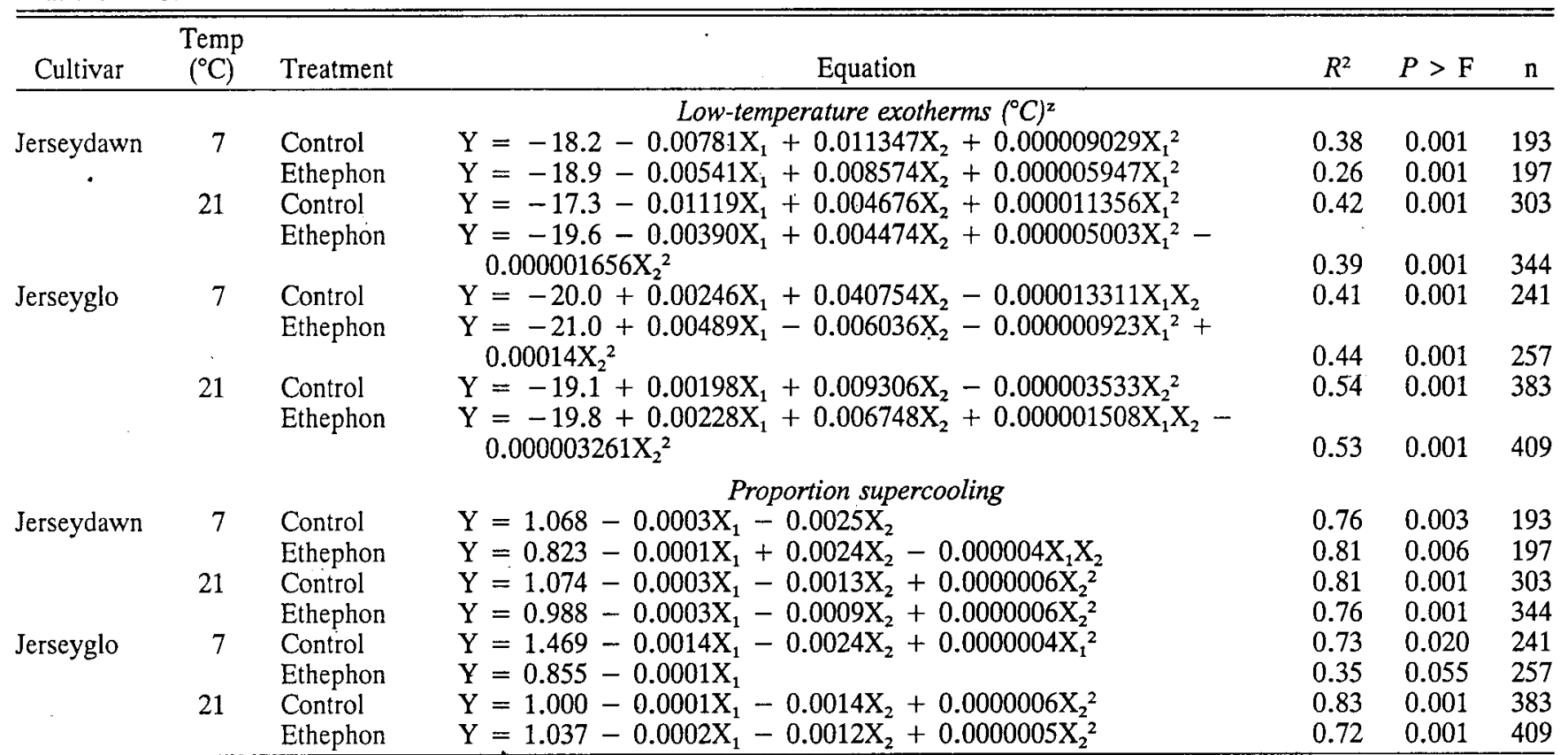

${ }^{2} \mathrm{X}_{1}=$ growing degree hours base $4.5 \mathrm{C}$ inthe field; $\mathrm{X},=$ growing degree hours base $4.5 \mathrm{C}$ during post-sampling incubation.

LTE (C)

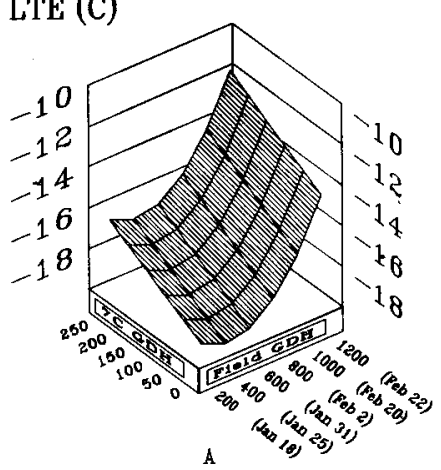

LTE (C)

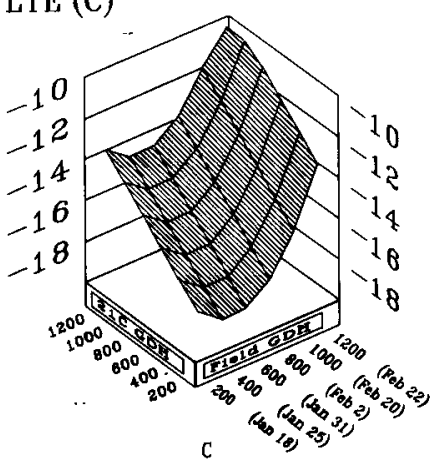

LTE (C)

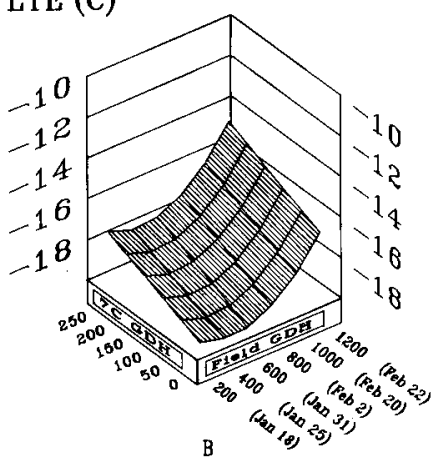

LTE (C)

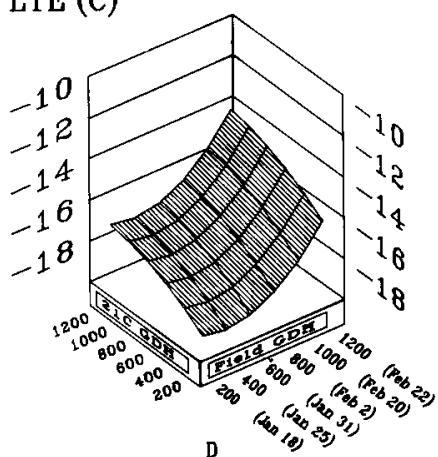

Fig.4. Predicted mean low-temperature exotherm values derived from equations in Table 2 for 'Jerseydawn' peach flower buds treated in October with ethephon at $100 \mathrm{mg} \cdot$ liter' for spring bloom delay then subjected to deacclimation at 7C (A and B) or 21C (C and D) the following January through March. (A and C) Controls, (B and D) ethephon-treated.

LTE (C)

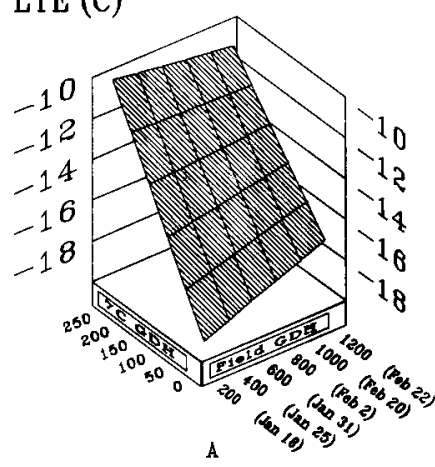

LTE (C)

LTE (C)
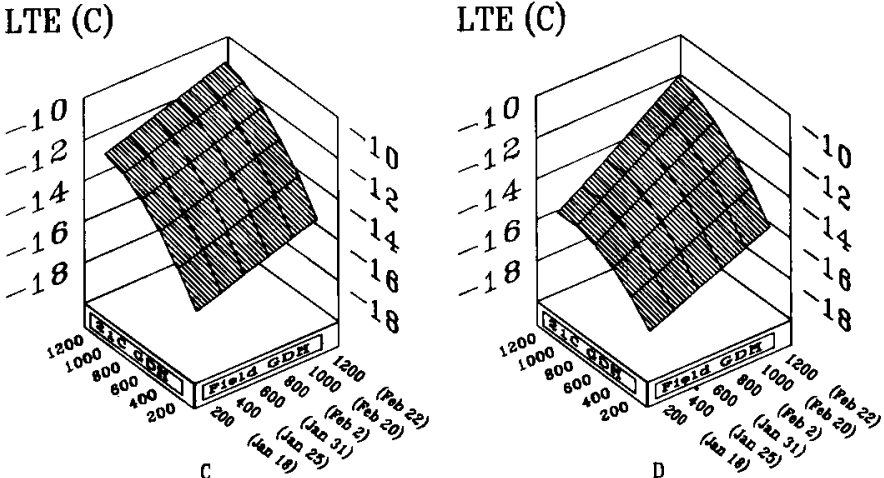

Fig. 5. Predicted meam low-temperature exotherm values derived from equations in Table 2 for 'Jerseyglo' peach flower buds treated in October with ethephon at $100 \mathrm{mg} \cdot \mathrm{liter}^{-1}$ for spring bloom delay then subjected to deacclimation at $7 \mathrm{C}(\mathbf{A}$ and $\mathbf{B})$ or $21 \mathrm{C}(\mathbf{C}$ and $\mathbf{D})$ the following January through March. (A and C) Controls, (B and D) ethephon-treated. 
at gradually higher temperatures as the dormant season progressed (Figs. 4 and 5).

The deacclimation due to field GDH accumulation was much less than deacclimation due to controlled deacclimation. Under the latter conditions, GDHs accumulated at a constant temperature, while field GDHs accumulated during fluctuating temperatures. Reacclimation of buds may have occurred in the field following deacclimation, thus the apparent slower deacclimation under field conditions. In both cultivars, the influence of controlled GDH accumulation on the mean LTE was most pronounced at $21 \mathrm{C}$. In 'Jerseydawn', it is unclear whether the decreased hardiness at $21 \mathrm{C}$ than at $7 \mathrm{C}$ is due to greater accumulation of GDHs at $21 \mathrm{C}$ or to greater pistil sensitivity to $21 \mathrm{C}$ than at $7 \mathrm{C}$. The difference in the shapes of the response surfaces of ethephon-treated and untreated buds in both cultivars suggests an intrinsic enhancement of hardiness in treated buds compared to untreated buds; as suggested by Durner (1989), rather than simply delayed deacclimation in the spring due to delayed pistil development in the fall (Herrera, 1986).

Between $80 \%$ and $100 \%$ of the flower buds supercooled before significant accumulation of field GDH (January) (Figs. 6 and 7). In both cultivars, ethephon treatment significantly reduced the number of buds that lost the ability to supercool after incubation at 7C. However, by the time buds had accumulated significant GDHs in the field (March), the effect of ethephon was much less pronounced. Nevertheless, a greater proportion of ethephon-treated 'Jerseyglo' buds supercooled even after accumulating $1300 \mathrm{GDH}$ in the field (Fig. 7b).

Ethephon appears to enhance flower bud hardiness in three distinct ways: 1) it decreases the mean LTE of the pistil, 2) it
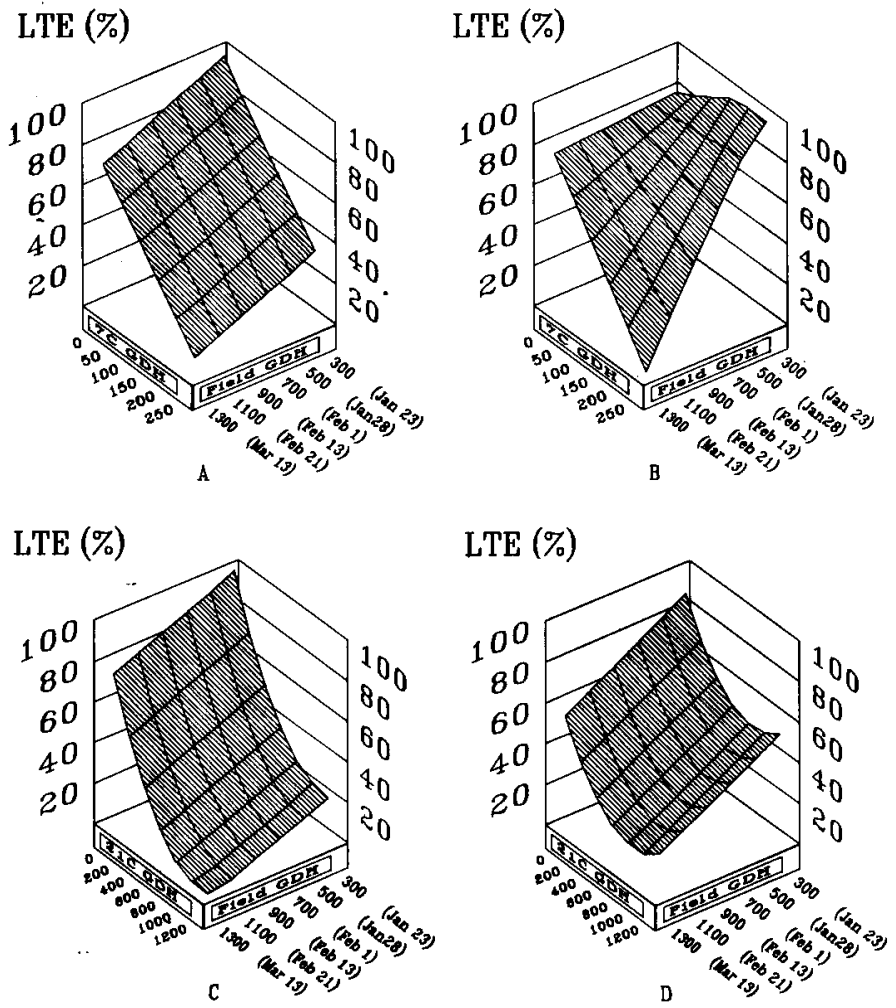

Fig. 6. Predicted proportions of buds supercooling derived from equations in Table 2 for 'Jerseydawn' peach flower buds treated in October with ethephon at $100 \mathrm{mg}$-liter' for spring bloom delay then subjected to deacclimation at $7 \mathbf{C}(\mathbf{A}$ and $\mathbf{B})$ or $21 \mathrm{C}(\mathbf{C}$ and $\mathbf{D})$ the following January through March. (A and C) Controls, (B and D) ethephon-treated. maintains the ability of flower buds to supercool under reacclimating conditions, and 3 ) it reduces the rate at which buds reacclimate.

The mechanism(s) by which ethephon enhances pistil hardiness is difficult to determine, given our limited understanding of the basis for cold hardiness at the cellular level. Quamme and Gusta (1987) proposed that peach flower primordia have an intrinsic resistance to ice nucleation that may be due to the formation of discontinuities in the liquid phase between the water in the supercooled primordium and the ice in surrounding tissues. This situation may prevent nucleation of pistil water by ice from bud scales or vascular traces (Cary, 1985). Pistils have also been found to have lower water and osmotic potentials than the surrounding tissues within the bud (Quamme and Gusta, 1987). Lower pistil water content could, therefore, lead to deeper supercooling (Quamme, 1983). The reduced osmotic potential of flower primordia could be due to higher sucrose levels in the primordia compared to the vascular tissues below the buds or the bud scales (Quamme and Gusta, 1987). High levels of sucrose in pistils could depress the supercooling point as well, Ashworth and Abeles (1984) have found that increasing the sucrose concentration of an aqueous solution will depress the nucleation temperature of the solution in small pores. Durner (1989) has shown that pistils from ethephon-treated trees have a higher sorbitol and sucrose content on a fresh-weight basis than buds from untreated trees. The effect on hardiness induced by ethephon in both container-grown and field trees, therefore, may be due partly to changes in the carbohydrate status of the bud, since differences in carbohydrate status would likely alter the osmotic environment of the bud (Quamme and Gusta, 1987).
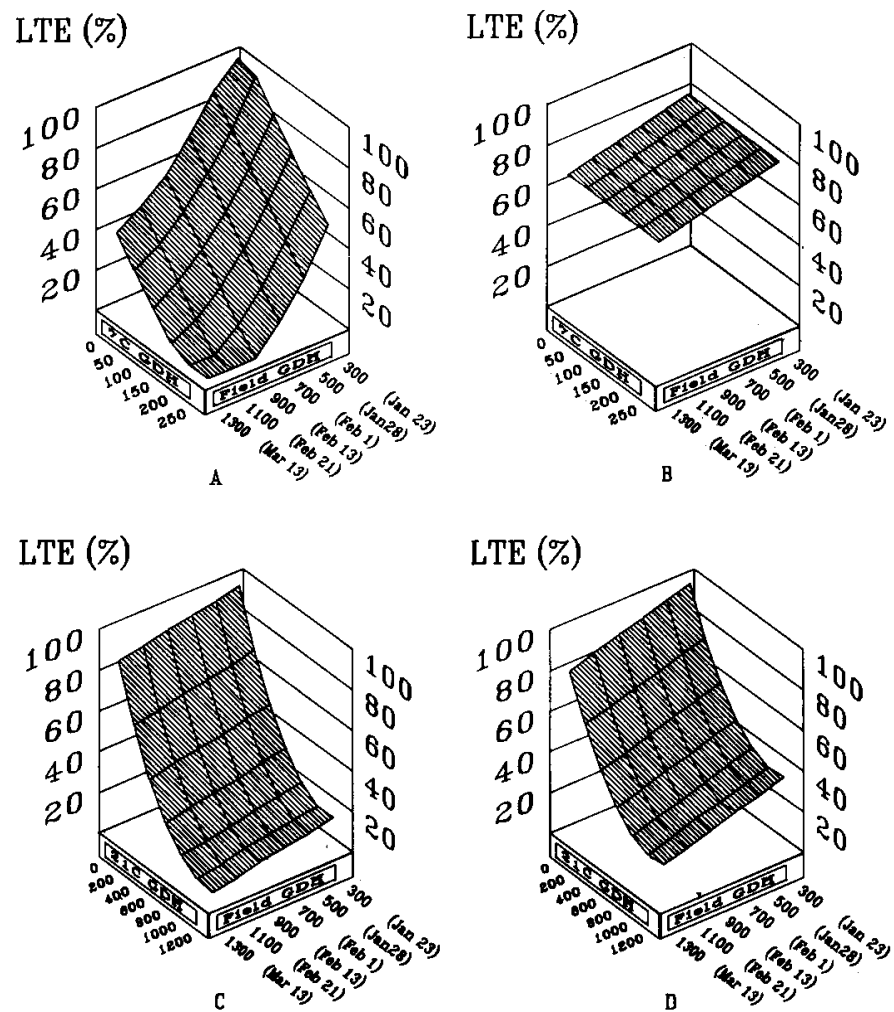

Fig. 7. Predicted proportions of buds supercooling derived from equations in Table 2 for 'Jerseyglo' peach flower buds treated in October with ethephon at $100 \mathrm{mg} \cdot \mathrm{liter}^{-1}$ for spring bloom delay then subjected to deacclimation at 7C (A and B) or 21C (C and D) the following January through March. (A and C) Controls, (B and D) ethephon-treated. 
Freezing of the bud under field conditions may accentuate the ethephon effect by concentrating the intracellular contents, thereby promoting full expression of the effect under natural conditions but not in non frozen container-grown trees.

In summary, as flower buds accumulated chilling hours, they became more responsive to elevated temperatures. They bloomed more quickly and also reacclimated more rapidly. Application of ethephon to dormant flower buds reduced the effectiveness of $5 \mathrm{C}$ to break the rest period. Their reduced response to elevated temperatures was reflected in a longer time to bloom and by reduced deacclimation. By increasing the chilling requirement of buds and, thus, prolonging flower bud dormancy, ethephon reduces the rate at which flower buds become increasingly sensitive to elevated temperatures. This response delays deacclimation during winter and delays bloom in the spring, and offers the potential to reduce economic losses due to low-temperature stress.

\section{Literature Cited}

Andrews, P. K., E.L. Proebsting, and G.S. Campbell. 1983a. An exotherm sensor for measuring the cold hardiness of deep-supercooled flower buds by differential thermal analysis. HortScience 18:77-78.

Andrews, P. K., E.L. Proebsting, and D.C. Gross. 1983b. Differential thermal analysis and freezing injury of reacclimating peach and sweet cherry reproductive organs. J. Amer. Soc. Hort. Sci. 108:755-759.

Apelbaum, A. and S.P. Burg. 1972. Effect of ethylene on cell division and deoxyribonucleic acid synthesis in Pisum sativum. Plant Physiol. 50:117-124.

Ashworth, E.N. and F.B. Abeles. 1984. Freezing behavior of water in small pores and the possible role in the freezing of plant tissues. Plant Physiol. 76:201-204.

Blanpied, G.D. 1972. A study of ethylene in apple, red raspberry and cherry. Plant Physiol. 49:627-630.

Cary, J.W. 1985. Freeze survival in peach and prune flowers. Plant Sci. Lett. 37:265-271.

Cooke, A.R. and D.I. Randall. 1968. 2-Haloethanephosphonic acids as ethylene releasing agents for the induction of flowering in pineapples. Nature (London) 218:964.

Coston, D. C., G.H. Krewer, T.E. Elkner, J.G. Williamson, and E.T. Sims, Jr. 1985. Chemical treatments to delay bloom in peach. J. Amer. Soc. Hort. Sci. 110:874-877.

Couvillon, G.A. and A. Erez. 1985. Influence of prolonged exposure to chilling temperatures on bud break and heat requirement for bloom of several fruit species. J. Amer. Soc. Hort. Sci. 110:47-50.

Couvillon, G.A., G.A. King, C.M. Moore, and P. Bush. 1975. Obtaining small peach plants containing all bud types for 'rest' and dormancy studies. HortScience 10:78-79.

Crisosto, C.H., P.B. Lombard, and L.H. Fuchigami. 1989. Fall ethephon delays bloom in 'Redhaven' peach by delaying flower differentiation during dormancy. J. Amer. Soc. Hort. Sci. 114:881-884.
Durner, E.F. 1989. Cryoprotection of reacclimating peach flower buds by ethephon alteration of pistil carbohydrate content. Cryobiology 26:290-296.

Durner, E.F. and T.J. Gianfagna. 1988. Fall ethephon application increases peach flower bud resistance to low-temperature stress. J. Amer. Soc. Hort. Sci. 113:404-406.

Fogle, H.W. 1973. Peach production east of the Rocky Mountains. U.S. Dept. Agr. Hdbk. 280.

Gianfagna, T. J., E.F. Durner, and G.S. Teiger. 1989. Reducing low temperature injury to peach flower buds with ethephon. Acts Hort. 239:203-206.

Gianfagna, T. J., R. Marini, and S. Rachmiel. 1986. Effect of ethephon and $\mathrm{GA}_{3}$ on time of flowering in peach. HortScience 21:69-70.

Halevy, A. H., R. Shilo, and S. Simchon. 1970.. Effect of 2-chloroethylphosphonic acid (ethrel) on health, dormancy and flower and corm yield of gladioli. J. Hort. Sci. 45:427-434.

Herrera, M. 1986. Effect of fall application of ethephon on peach floral bud growth and development. MS Thesis, Rutgers Univ., New Brunswick, N.J.

Imanishi, H. and E.J. Fartanier. 1983. Effects of exposing freesia corms to ethylene or to smoke on dormancy-breaking and flowering. Scientia Hort. 18:381-389.

Irving, D.E. 1987. 'Fantasia' nectarine: Effects of autumn-applied ethephon on blossoming and cropping. New Zealand J. Expt. Agr. 15:67-72.

Nell, T.A., W.H. Bodnaruk, J.N. Joiner, and T.J. Sheehan. 1983. Ethylene evolution and flowering of cold- and GA-treated 'Redwing' azaleas. HortScience 18:454-455.

Proebsting, E. L., Jr, and H.H. Mills. 1969. Effects of growth regulators on fruit bud hardiness in Prunus. HortScience 4:254-255.

Proebsting, E. L., Jr, and H.H. Mills. 1976. Ethephon increases cold hardiness of sweet cherry. J. Amer. Soc. Hort. Sci. 101:31-33.

Quamme, H.A. 1978. Mechanism of supercooling in overwintering peach flower buds. J. Amer. Soc. Hort. Sci. 103:57-61.

Quamrne, H.A. 1983. Relationship of air temperature to water content and supercooling of overwintering peach flower buds. J. Amer. Soc. Hort. Sci. 108:697-701.

Quamme, H.A. and L.V. Gusta. 1987. Relationship of ice nucleation and water status to freezing patterns in dormant peach flower buds. HortScience 22:465-467.

Richardson, E. A., S.D. Seeley, D.R. Walker, J.L. Anderson, and G.L. Ashcroft. 1975. A model for estimating the completion of rest for 'Redhaven' and 'Elberta' peach trees. HortScience 9:331-332.

Snedecor, G.W. and W.G. Cochran. 1980. Statistical methods. The Iowa State Univ. Press, Ames.

Warner, H.L. and A.C. Leopold. 1969. Ethylene evolution from 2chloroethylphosphonic acid. Plant Physiol. 44:156-158.

Weisberg, S. 1985. Applied linear regression. Wiley, New York.

Yang, S.F. 1969. Ethylene evolution from 2-chloroethylphosphonic acid. Plant Physiol. 44:1203-1204.

Zimmerman, R. H., M. Lieberman, and O.C. Broome. 1977. Inhibitory effect of a rhizobitoxine analog on bud growth after release from dormancy. Plant Physiol. 59:158-160. 